Алакаев Евгений Александрович

адъюнкт кафедры социологии

Военного университета

Министерства обороны Российской Федерации

\section{ЦЕННОСТНЫЕ ОРИЕНТАЦИИ МОЛОДЕЖИ 1990-Х - НАЧАЛА 2010-Х ГГ.}

\section{Аннотация:}

В статье на основании данных, полученных в результате социологических исследований, рассматриваются основные тенденции изменения ценностных ориентаций российской молодежи 19902010-х ге. в разных сферах общественной жизни. Автор систематизировал эмпирический материал, представил ценностный социологический портрет молодежи, выявил индикатор для диагностирования выхода общества из состояния аномии.

Ключевые слова:

молодежь, ценности, ценностные ориентации, аномия, социологические исследования, политические ценности, здоровье, семейные ценности.

\section{Alakaev Evgeny Aleksandrovich}

Postgraduate student, Social Science Department, Military University of the Ministry of Defence of the Russian Federation

\section{YOUTH VALUE ORIENTATIONS OF THE 1990S - EARLY 2010 S}

Summary

Based on data obtained as a result of sociological re search the article examines the main changing trends in value orientations of the Russian youth of the 1990s - early 2010s in different spheres of public life. The author systematized the available empirical material, expressed a valuable sociological portrait of the Russian young people, identified a diagnosing indicator for the society to be out of anomie.

Keywords: youth, values, value orientations, anomie, sociological research, political values, health, family values.

В условиях продолжающегося с 90-х гг. XX в. перехода от советского общества к постиндустриальному наблюдается смена ценностей всех групп российского населения, а соответственно - имеется и должный интерес к ценностным ориентациям социума со стороны исследователей. В период столь существенных общественных преобразований именно ценности можно считать ключевым индикатором, определяющим влияние этих изменений на общество и отдельные социальные категории граждан. Несомненно, что столь актуальная проблема нашла отражение и в работах авторов, публикующихся в журнале «Социологические исследования».

Под ценностными ориентациями следует понимать относительно устойчивые избирательные отношения индивида к тем или иным духовным и материальным благам, позволяющим удовлетворять потребности в процессе жизнедеятельности [1]. Они усваиваются человеком посредством механизма социализации [2]. Ценностные ориентации подразделяются на девиантные (отклоняющиеся) - не соответствующие социальным ожиданиям - и нормативные - не выходящие за рамки принятых в обществе образцов социального поведения людей [3].

Всего за рассмотренный период с 1991 по 2014 г. в журнале «Социологические исследования» были опубликованы 122 статьи, в той или иной степени затрагивавшие тему социальных ценностей и ценностных ориентаций. Таким образом, отмечается стабильный интерес социологов к аксиологическим проблемам общества. Ежегодно за указанный промежуток времени, за исключением 1992 и 1996 гг., в свет выходили от 2 до 10 работ ценностной направленности, из них наибольшее количество - в 1997, 2007 и 2011 гг. (рисунок 1).

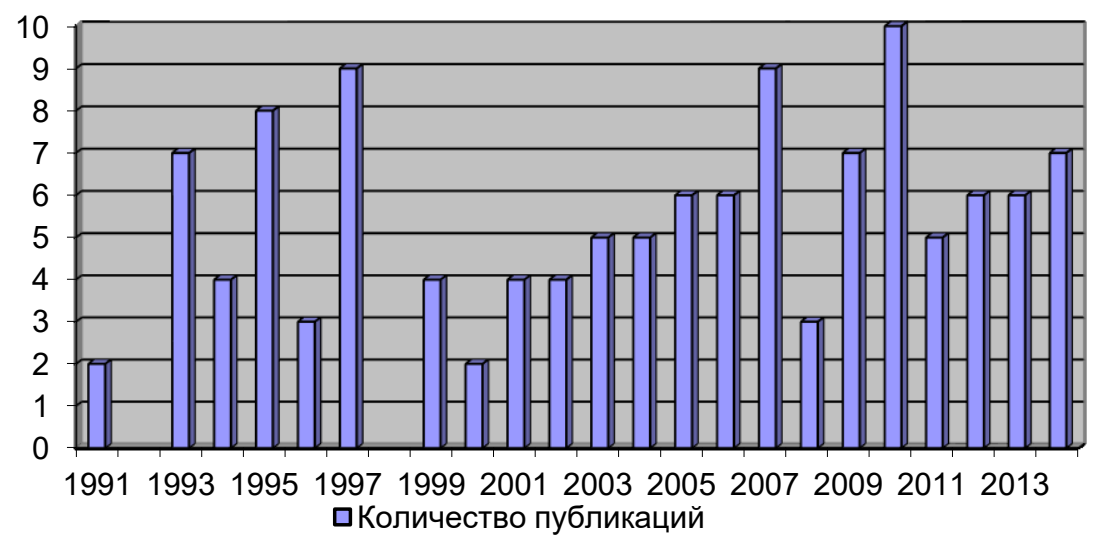

Рисунок 1 - Количество публикаций в журнале «Социологические исследования», посвященных ценностям и ценностным ориентациям граждан 
Устойчивый интерес социологов к проблемам ценностных установок и ориентаций молодежи отмечается с первой половины 2000-х гг., хотя отдельные публикации приходились и на середину и конец 1990-х гг. В связи с этим особенно актуально рассмотрение ценностных ориентаций российских молодых людей, так как очевиден ценностный конфликт молодого и взрослого поколений, усугубленный общей аномией социума. Его характеризует затрагивание фрилософских, мировоззренческих основ дальнейшего развития общества и человека. Взрослое поколение оказалось в ситуации, когда передача ценностных установок преемникам практически отсутствует, порождая тем самым разрыв между поколениями, а следовательно, и фррагментарность исторической преемственности.

Тематическое распределение аксиологических публикаций в журнале показало, что наибольшей популярностью у авторов пользовались темы, связанные с ценностями молодежной среды (27 статей), а также российского общества или его отдельных региональных групп (25). Кроме того, довольно значительный объем работ пришелся на общую социологическую теорию ценностей, а также анализ взглядов классиков на аксиологические вопросы в социологии (14). Экономические, политические и религиозные ценности также пользовались популярностью, но массив публикаций по ним значительно меньше (9, 8 и 7 соответственно). Ценности, относящиеся к военной службе, рассматривались в незначительном объеме и были затронуты только в двух статьях в начале 1990-х гг. (рисунки 2, 3).

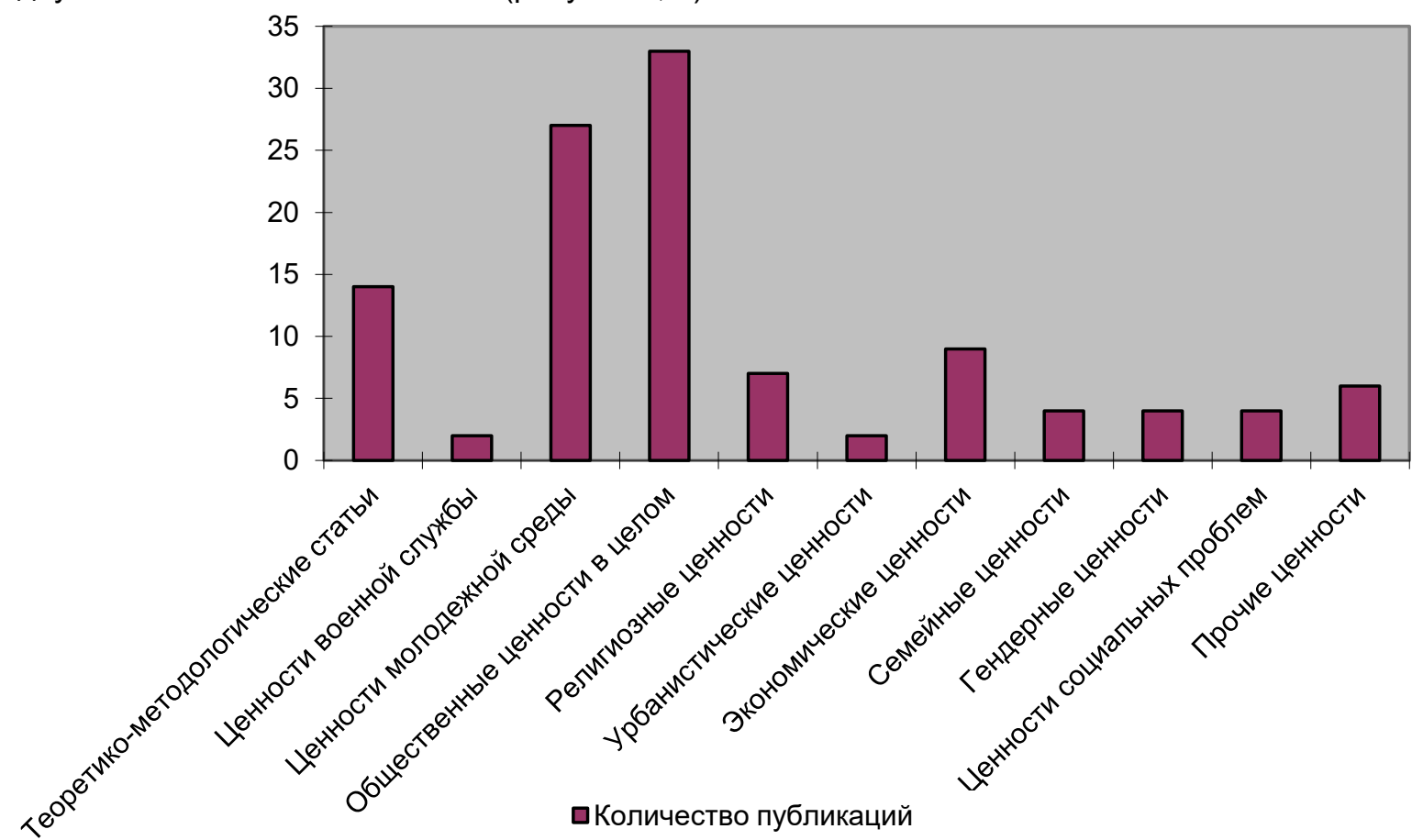

Рисунок 2 - Количество публикаций, посвященных разным ценностным категориям

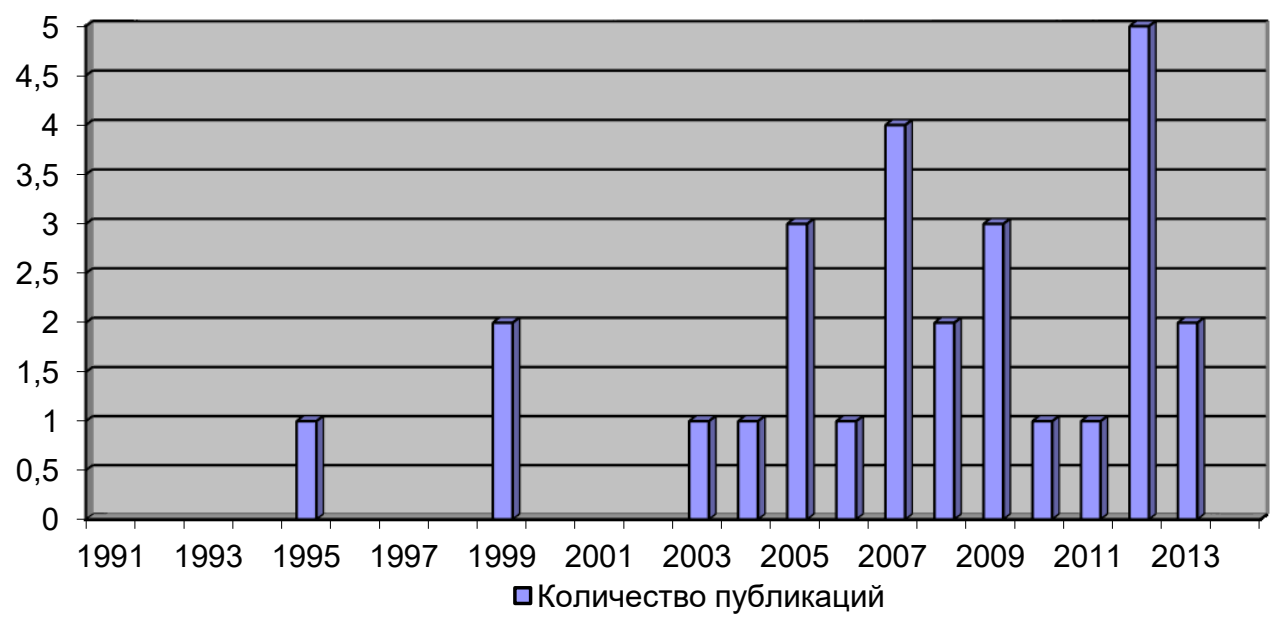

Рисунок 3 - Количество публикаций, посвященных ценностям и ценностным ориентациям молодежи 
В ценностных ориентациях молодежи можно выделить несколько значимых показателей, которые, с одной стороны, устойчиво определяются практически во всех исследованиях, а с другой - имеют различия в отношении к ним респондентов в зависимости от года анализа. При этом некоторые исследования дают возможность сопоставить представленные в них показатели с данными советского периода.

Обобщенными параметрами могут служить жизненные цели и образ жизни, отношение к учебе, будущей профессии, планированию семьи, старшему поколению, своему здоровью, а также политические предпочтения. Рассмотрим каждую категорию подробнее.

Смысложизненные ценности, выраженные в жизненной цели, претерпели значительные изменения в сторону резкого ослабления взглядов альтруистической направленности и увеличения материально-прагматического компонента. Разберем динамику смысложизненных ценностных ориентаций молодежи в хронологическом порядке.

Так, в 1999 г. основной жизненной целью 80,0 \% молодых людей считали обеспечение материального благополучия, при этом 40,0 \% из них в качестве идеального образа жизни видели возможность «жить беззаботно, развлекаться», «делать всегда то, что хочется» (71,0 \%), «быть очень хорошо материально обеспеченным» (59,0 \%). Около 50,0-60,0 \% представителей молодого поколения связывали мотивацию трудовой деятельности исключительно с деньгами и стремлением заработать их любыми средствами, в том числе противоправными. Данные 1970-х гг. свидетельствуют, что тогда представление молодежи о счастье было иным: 35,6 \% опрошенных видели его в возможности приносить людям пользу, 44,8 \% - в удовлетворенности своей работой [4].

Исследования красноярских социологов показывают, что по сравнению с данными 1988 г. в массовом сознании студентов в 2004 г. резко усилились прагматические тенденции, прежде всего ориентация на материальное благополучие, при ослаблении созидательно-альтруистической ориентации. Так, если в 1988 г. 42,0 \% респондентов полагали, что жить необходимо для того, чтобы приносить «наибольшую пользу окружающим», то в 2004 г. количество студентов, отмечающих значимость этой цели, снижается в 10 раз - до 4,1 \%. Доля указавших «стремление помогать людям» уменьшилась более чем в 6 раз - с 32,0 \% в 1988 г. до 5,0 \% в 2004 г. Ценность «уважение окружающих», занимавшая второе место в предпочтениях опрошенных в 1988 г. (57,4 \%), в 2004 г. представляется актуальной в качестве жизненной цели лишь для 17,2 \% опрошенных [5].

Два года спустя, в 2006 г., молодежь в той или иной степени допустимыми считает такие действия, как уклонение от налогов - 31,6 \%, воинской службы - 33,3, присвоение найденных вещей - 47,2 \% [6]. В том же году в иерархии ценностей студентов материальное благосостояние оказалось важно для 57,9 \% из них [7]. По мнению опрошенных в ходе исследования 2007 г., достижению жизненного успеха в большей степени могут способствовать «связи, знакомства» $(68,0 \%)$, «хорошее материальное положение» $(58,8$ \%). В то же время немаловажными являются «качественное образование» $(52,8$ \%), «востребованная специальность» $(25,2)$, «положение семьи» $(28,4)$ и «стечение обстоятельств, случай» $(20,4$ \%). Такие факторы успешности, как «личностные качества» и «стремление к успеху», были названы лишь 1,2 и 0,4 \% соответственно. Вместе с тем респонденты видят связь между индивидуальными усилиями и успешностью: $66,0 \%$ участников опроса ради достижения успеха готовы получить дополнительное образование; 56,4 \% - работать «не покладая рук»; позицию «выехать за рубеж» отметили 43,2 \%; 38,8 \% готовы «пойти на риск или авантюру». Каждый седьмой-восьмой способен «поступиться своими принципами» (13,2 \%), «нарушить закон» (12,0 \%) [8].

Результаты опроса 2009 г. иллюстрируют, что большинство молодых людей $(55,0$ \%) считает, что их успех в жизни во многом зависит от умения вовремя закрывать глаза на собственные принципы и соглашаться с тезисом, что «современный мир жесток, и, чтобы добиться успеха в жизни, иногда приходится переступать через моральные принципы и нормы». При этом 45,0 \% респондентов не считают зазорным использование сексуальных связей в корыстных целях, уклонение от налогов и дачу взяток. Противоположной точки зрения - «лучше не добиться успеха, но не переступить через нормы морали» - придерживаются 44,0 \% студентов [9].

К 2012 г. успех в жизни с трудовыми ценностями связывает только каждый четвертый респондент, с профессиональными - каждый шестой. Среди фракторов, обеспечивающих достижение успеха в жизни, по-прежнему приоритетными являются связи и знакомства с нужными людьми (в 1999 г. их роль отметили 30,0%, в 2012 г. - 42,0 \%) [10].

Таким образом, при стабильном развитии ориентаций молодежи на повышение собственного материального благополучия отмечаются негативные тенденции, связанные со снижением добросовестности и моральной составляющей этого процесса. Значительное число молодых людей допускает возможность криминализации своего заработка, а также нечестной конкуренции на рынке труда, связанной с коррупционными знакомствами.

Затрагивая профессиональные ценности, отметим, что в 1999 г. при выборе подростками жизненных занятий доминируют такие, как «бизнесмен», «коммерсант»; среди престижных «про- 
фессий» называются «новый русский» и «крутой». В исследовании 1970-х гг. в качестве преобладающей зафиксирована ориентация молодежи на интересный, содержательный труд. Этот мотив стоял на первом месте у 53,7 \% опрошенных [11].

Ориентация на высокий заработок была свойственна лишь 12,3 \% опрошенных. На гуманистический мотив - возможность «приносить людям пользу» - указали около 60,0 \% респондентов. Среди наиболее престижных профессий преобладали инженер - 35,0 \%; врач - 23,0; военный 18,0; учитель - 15,0 \%. В 1999 г. ни один из школьников не отнес к категории престижных профессии учителя и инженера. Таким образом, можно отметить четко выраженную эгоистическую и корыстную направленность жизненных планов и трудовых ориентаций опрашиваемой молодежи [12].

В 2003 г. привлекательные для студентов виды профессиональной занятости распределились так, \%: предприниматели, имеющие собственное дело, - 70,0; менеджеры или сотрудники частных фирм - 16,0; государственные служащие - 10,0; ученые, педагоги, писатели - 2,0; домохозяйки - 2,0. Для опрошенных была характерна готовность к предпринимательскому риску 70,0 \% студентов-гуманитариев видели себя в будущем в качестве владельца частной фрирмы. Гарантированной государственной зарплате предпочиталась конкурентная борьба, требующая огромных усилий и особой «предпринимательской самореализации». Более двух третей респондентов не боялись самоотверженного труда [13].

В 2007 г. опрошенная петербургская молодежь более всего ценила деятельность врача $(65,0 \%)$, ученого $(48,0)$, предпринимателя (33,0 \%). Затем следуют творческая деятельность художественной интеллигенции в широком смысле $(28,0$ \%) и только потом такие основополагающие виды деятельности, как труд инженера $(19,0)$ и рабочего $(18,0 \%)$. Педагогическую профрессию выбирали всего 2,6 \% респондентов, в первую очередь девушки [14].

Данные 2009 г. показывают, что «основать свое дело» стремились 17,2 \% молодых людей, «работать по специальности в государственных структурах» - 16,6 \%. Удовлетворенность профессиональным образованием проявлялась в предпочтениях работать по специальности. Получение образования рассматривалось как инвестиция в статусную позицию. Молодежь активно планировала будущее и готова была брать на себя ответственность, поэтому на передний план выходила организация собственного бизнеса как способ преодоления классической схемы карьерного роста и освоения новых возможностей жизненного успеха, основанный на другом типе культурного капитала (собственных силах, деньгах, власти). Совсем небольшая часть респондентов связывала трудовую деятельность с научно-исследовательской сферой - 2,2 \%. Молодежь не стремилась в науку прежде всего из-за низкого уровня зарплаты [15].

Ситуация в сорере семейных ценностей несколько более радужная. В 1999 г. их в качестве приоритета выбрали 65,0 \% опрошенных; в 2002 - уже 72,0; 2003 - 60,0; 2007 - 78,0 \%, то есть в целом создание семьи и воспитание детей остаются на первом месте для 60,0-70,0 \% молодых людей [16]. Опрос пензенских выпускников 2005/2006 учебного года показал, что доминирующее положение в иерархии ценностей молодежи заняла семья - 94,5 \% респондентов отметили эту категорию в качестве основополагающей [17].

Таким образом, можно говорить о важности семейных отношений в молодежной среде. Так, согласно исследованию, опубликованному в 2009 г., они наиболее значимы для молодежи 25-30 лет - 13,1 \%; 18-24 - 12,3; 14-17 - 10,4 \%. Осознание ценности семьи выражается в фриксации отрицательного отношения к одиночеству в жизненном сценарии у 66,2 \% юношей и девушек [18].

Рассмотрим отношение к старшему поколению. Исследование 2007 г. показало, что в процессе социализации и воспитания вне конкуренции остается влияние родителей, прежде всего матери (58,0 \% опрошенных) и в меньшей степени отца (44,0 \%) [19]. По данным опроса 2008 г. молодежь в целом считает, что государство и власть должны заботиться о стариках не меньше, чем о детях (72,4%). Это, видимо, вызвано низким уровнем социального обеспечения граждан [20].

Политические ценности отражались в исследованиях с 2003 г. Они частично подтвердили мнение о политической пассивности постсоветской молодежи, о том, что ее мало волновали проблемы политики и гражданственности. Так, в 2003 г. только 45,0 \% опрошенных осознавали себя гражданами России, знали свои конституционные права и обязанности. В свою очередь 27,031,0 \% респондентов не задумывались о будущем страны, предпочитая заниматься личными делами, хотя гражданство хотели сохранить. Желание поменять гражданство, если это окажется выгодным и полезным, выразили 24,0-28,0 \% молодых людей. Интересовались политикой, принимали участие в выборах 22,0 \% опрошенных. Иногда участвовали в выборах около 70,3 \% респондентов, не ходили на них и не интересовались политикой 11,6 \% [21].

В личных и групповых интервью студенты обычно заявляли о своей аполитичности, недоверии к политике и политиканству, разочаровании в демократических идеалах. При этом с начала 2000-х гг. стали отчетливо проявляться патриотические ценностные ориентации, особенно в отношении к отечественной истории. В 2003 г. получены следующие результаты, \%: гордятся историей государства в целом - 41,0; гордятся историей России, но стыдятся истории СССР - 55,0; стыдятся отечественной истории - 4,0. В целом относительно недавнюю историю СССР, которая творилась руками отцов и дедов, 59,0 \% сыновей и внуков оценивают негативно [22]. 
В 2008 г. практически поровну распределилось отношение между теми, кто признает важность роли государства и правоохранительных органов в обеспечении личной безопасности человека (48,3 \%), и считающими, что человеку о своей безопасности приходится заботиться самому, действуя в соответствии с собственным чувством справедливости (51,7 \%). При этом порядка 60,5 \% респондентов отмечают ощущение «сплоченности страны» [23]. Это говорит о далеко зашедших в Российской Федерации процессах распада культивировавшихся в СССР представлений о себе как «советском/постсоветском народе» и формировании национальной самоидентификации на базе имеющегося в настоящее время государственного разделения.

Состояние здоровья стабильно является приоритетным для молодых людей. Опрос 1999 г. показал, что 83,0 \% опрошенных хотят «иметь хорошее здоровье» [24]. При этом подобное желание несколько расходится с врачебной практикой. Так, в 2003 г. вузовские медики признали практически здоровыми лишь 68,0 \% первокурсников. Специализированное исследование здоровья молодежи 2005 г. выявило, что ответы на вопрос: «Насколько проблема здоровья важна для вас?» - распределились следующим образом. Треть опрошенных считают эту проблему самой важной. Почти половина респондентов отметили, что она не менее важна, чем другие. Для 20,0 \% данная проблема имеет ситуативный характер, о ней вспоминают, когда испытывают недомогания. Только 4,0 \% опрошенных не считают ее значимой. Различия при ответе на этот вопрос между юношами и девушками не наблюдаются [25].

Согласно исследованию, опубликованному в 2006 г., здоровье одной из главных ценностей жизни считают 68,1 \% опрошенных молодых людей. Однако по-прежнему существует диссонанс между декларируемой, осознаваемой ценностью здоровья и реальным поведением, направленным на его сохранение и укрепление [26].

Таким образом, ключевые ценностные изменения в обществе можно определить по изменению отношения к главным жизненным ценностям. Здесь следует уточнить, что говорить о динамике трансформаций ценностных ориентаций в полной мере неправомочно, поскольку исследования несколько фрагментарны. Однако на основании имеющихся данных можно рассуждать о некоторых тенденциях.

Охваченный эмпирическим материалом период условно разделили на два временных отрезка: 1999-2005, 2006-2015 гг. Исследования по каждому из них отражены на рисунке 4.

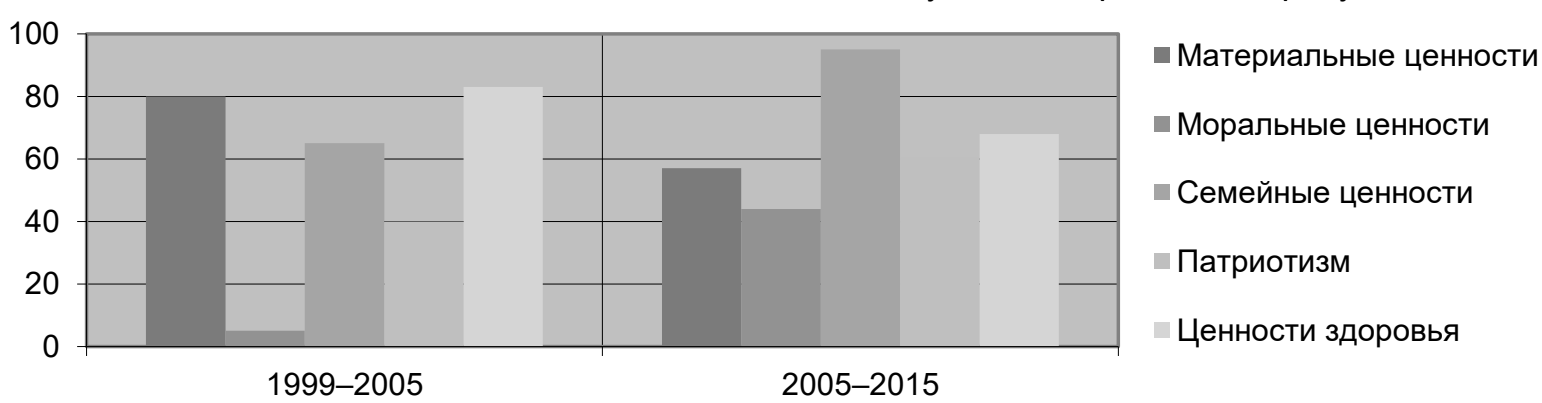

Рисунок 4 - Динамика ценностных ориентаций молодежи в 1999-2015 гг.

В 1999-2005 гг. основополагающей жизненной ценностью молодежи является материальное благополучие $(80,0$ \%), стремление помогать людям и приносить пользу окружающим актуально только для 4,0-5,0 \% опрошенных. При этом пойти на некоторые правонарушения или аморальные поступки в целях приобретения материальных благ готовы порядка 50,0 \% респондентов. Положительные семейные ценности стабильно разделяет 65,0 \% молодых людей, поскольку, видимо, «обесцениванию» более подвержены ценности, связанные с материальными и карьерными отношениями, а не затрагивающие традиционный семейный уклад. Ответственно подходили к правам и обязанностям гражданина Российской Федерации только 45,0 \% опрошенных, патриотические настроения характерны для 41,0 \%. Стремление обладать хорошим здоровьем обозначили 83,0 \% студентов. В целом данный временной промежуток можно охарактеризовать как социальную аномию, продолжающуюся с начала 1990-х гг. Концентрация на материальном благосостоянии и утрата моральных авторитетов в период экономической стагнации конца XX в. по естественной инерции сохранялись вплоть до середины 2000-х гг.

C 2006 по 2010 г. материальное благосостояние остается важным примерно для 57,0 \% опрошенных, при этом становятся значимыми качество образования $(53,0)$ и усердие в работе $(56,0 \%)$. Однако с 2011 г. наметились негативные тенденции в вопросах отношения к работе и карьере. Например, успешность жизни с трудовой деятельностью связывали только 25,0 \% молодых людей. Преступить ради успеха моральные нормы готовы 45,0 \% респондентов. Семейные ценности актуальны для 95,0 \%. Важность патриотических ценностей отмечали 60,5 \% опрошенных. Здоровье 
как значимую жизненную категорию определили 68,0 \% респондентов, что меньше, чем в 19992005 гг., но в целом снижение этого показателя не носит угрожающего характера.

Таким образом, во время некоторого экономического подъема в стране и соответствующего повышения благосостояния граждан, наметившихся с середины 2000-х гг., несколько усилились позиции лиц, ориентированных на мораль, однако нацеленность на материальный достаток тоже весьма сильна. В качестве негативной тенденции с 2011 г. можно отметить снижение заинтересованности молодых людей в трудовой деятельности. Подобная закономерность в наложении на все более явный спад в экономике вполне может привести к возвращению к ситуации аномии 90-х гг. XX столетия.

Основным способом сбора первичной информации о ценностных ориентациях молодежи за рассматриваемый период стал анкетный опрос, он применялся в 24 исследованиях. В двух случаях использован метод анализа документов (в данном случае сочинений и автобиографий). Некоторые социологи отдельно выделяют изучение автобиографий, но, как нам видится, его целесообразно рассматривать в рамках анализа документов. Один раз в качестве базового был задействован метод интервьюирования респондентов. Иногда анкетный опрос дополняли еще рядом методик. Так, результаты социологического исследования молодежи, опубликованного в 2003 г., включали данные, полученные посредством личностного тестирования, ведения дневников, групповых массовых интервью, а также мыслительного эксперимента, приближавшегося, по утверждению автора, к нарративному интервью [27].

Исследование, опубликованное в 2004 г., помимо анкетного опроса содержало результаты наблюдения и интервьюирования преподавателей (сущностно-экспертного опроса) [28]. Экспертный опрос дополнял массовое анонимное анкетирование еще дважды. В исследовании 2006 г. также в качестве дополнительного метода использовали тестирование смысложизненных ориентаций [29], 2007 г. - полуструктурированное интервью, метод неоконченных предложений и опрос в трех фрокус-группах [30]. Средняя выборка составляла порядка 400-500 человек, но иногда размер выборки не превышал 1000 опрошенных.

Следует отметить, что с 2000-х гг. методика изучения молодежной среды совершенствуется, исследования становятся более многоплановыми, а сами исследователи пользуются достаточно широким арсеналом способов, дополняющих и уточняющих основной анкетный опрос. Наиболее масштабные и многогранные из них были опубликованы в 2003, 2004 и 2008 гг.

Нынешнее состояние российского общества можно квалифицировать как затянувшуюся аномию. Согласно теории Э. Дюркгейма, этим понятием можно обозначить ценностно-нормативный вакуум, характерный для переходных и кризисных периодов развития социума, когда старые нормы и ценности перестают действовать, а новые еще не установились. Аномию Э. Дюркгейм объяснял неразработанностью правил, регулирующих отношения между социальными функциями, которые не приспособлены друг к другу. Подобный кризис ведет к ценностно-нормативному вакууму, отсутствию общепризнанных норм и ценностей, моральному беспорядку.

Несомненно, такое состояние общества вызывает интерес у социологов, что хорошо характеризует массив статей 1990-х - начала 2010-х гг., посвященных ценностным ориентациям граждан. С конца 1990-х гг. важное место в нем занимают публикации о ценностных ориентациях молодежи. Данная категория в них предстает динамичной социальной группой, в которой противоречиво развиваются тенденции достижения материального и семейного благополучия, стремления к национальному самовыражению и общего ослабления альтруистических ориентаций.

Скорее всего, в дальнейшем следует прогнозировать развитие материальной и национальной составляющих ценностных ориентаций молодых людей, в то время как альтруистические мотивации, вероятно, достигли «дна», что позволяет ожидать их возрождения. Последнее может быть обусловлено достижением значительной частью населения удовлетворительного, с их точки зрения, материального благополучия и стабильного социального положения, в котором излишки материальных благ распределяются собственниками между нуждающимися. Таким образом, развитие альтруистических ценностных ориентаций, если оно отразится в последующих социологических исследованиях, может выступать индикатором достижения обществом социальной стабильности и выхода из состояния аномии, наблюдаемого с начала 1990-х гг.

\section{Ссылки:}

1. Малинаускас Р.К. Динамика ценностных ориентаций литовских студентов // Социологические исследования. 2006. № 11.

2. Parsons T. The place of ultimate values in sociological theory // International Journal of Ethics. 1935. Vol. 45, no. 3. P. 287.

3. Соколов А.В., Щербакова И.О. Ценностные ориентации постсоветского гуманитарного студенчества // Социологические исследования. 2003. № 1 .

4. Попов В.А., Кондратьева О.Ю. Изменение мотивационно-ценностных ориентаций учащейся молодежи // Там же. 1999. № 6. 
5. Казарина-Волшебная Е.К., Комиссарова И.Г., Турченко В.Н. Парадоксы трансформации ценностных ориентаций российской молодежи // Там же. 2012. № 6.

6. Бояк Т.Н. Духовно-нравственные ценности сельской молодежи (на материалах Бурятии и Читинской области) // Там же. 2008. № 4.

7. Козина Г.Ю. Здоровье в ценностном мире студентов // Там же. 2007. № 9.

8. Самсонова Е.А., Ефимова Е.Ю. Молодежь Тулы: ценностные ориентации и реалии повседневной жизни // Там же. 2007. № 11 .

9. Орлова В.В. Ценностные приоритеты молодежи в Сибирском регионе // Там же. 2009. № 6 .

10. Банникова Н.Л., Боронина Л.Н., Вишневский Ю.Р. Новые явления в ценностных ориентациях уральского студенчества // Там же. 2013. № 2 .

11. Попов В.А., Кондратьева О.Ю. Указ. соч.

12. Там же.

13. Соколов А.В., Щербакова И.О. Указ. соч.

14. Орлова В.В. Указ. соч

15. Явон С.В. Ценностные ориентации молодежи Среднего Поволжья // Социологические исследования. 2012. № 5.

16. Там же.

17. Козина Г.Ю. Указ. соч.

18. Явон С.В. Указ. соч.

19. Семенов В.Е. Ценностные ориентации и проблемы воспитания современной молодежи // Социологические исследования. 2007. № 4.

20. Петров А.В. Ценностные предпочтения молодежи: диагностика и тенденции изменений // Там же. 2008. № 2.

21. Соколов А.В., Щербакова И.О. Указ. соч.

22. Там же.

23. Петров А.В. Указ. соч.

24. Попов В.А., Кондратьева О.Ю. Указ. соч.

25. Цветкова И.В. Здоровье как жизненная ценность подростков // Социологические исследования. 2005. № 11.

26. Орлова В.В. Указ. соч.

27. Соколов А.В., Щербакова И.О. Указ. соч.

28. Особенности подготовки и ценностных представлений учащихся этнонациональных школ Севера / М.Ю. Мартынов, Е.В. Дорогонько, М.А. Ненашев, В.В. Шадрина // Социологические исследования. 2004. № 3.

29. Малинаускас Р.К. Указ. соч.

30. Петров А.В. Указ. соч.

\section{References:}

Bannikova, NL, Boronina, LN \& Vishnevsky, YuR 2013, 'New phenomena in the value orientations of the Ural students', Sotsiologicheskiye issledovaniya, no. 2, (in Russian).

Boyak, TN 2008, 'Spiritual and moral values of rural youth (by case study of Buryatia and the Chita region)', Sotsiologicheskiye issledovaniya, no. 4, (in Russian).

Kazarina-Volshebnaya, EK, Komissarova, IG \& Turchenko, VN 2012, 'Paradox of the value orientations' transformation among Russian youth', Sotsiologicheskiye issledovaniya, no. 6, (in Russian).

Kozina, GYu 2007, 'Health in the value world of students', Sotsiologicheskiye issledovaniya, no. 9, (in Russian)

Malinauskas, RK 2006, 'Dynamics of value orientations of Lithuanian students', Sotsiologicheskiye issledovaniya, no. 11, (in Russian).

Martynov, MYu, Dorogonko, EV, Nenashev, MA \& Shchadrina, VV 2004, 'Features of preparation and value representations of students at North ethnic national schools', Sotsiologicheskiye issledovaniya, no. 3, (in Russian).

Orlova, VV 2009, 'Value priorities of youth in the Siberian region', Sotsiologicheskiye issledovaniya, no. 6, (in Russian)

Parsons, T 1935, 'The place of ultimate values in sociological theory', International Journal of Ethics, vol. 45, no. 3, p. 287, https://doi.org/10.1086/intejethi.45.3.2378271.

Petrov, AV 2008, 'Value preferences of young people: changes detection and trends', Sotsiologicheskiye issledovaniya, no. 2, (in Russian)

Popov, VA \& Kondratyeva, OYu 1999, 'Changes in the motivational and value orientations of students', Sotsiologicheskiye issledovaniya, no. 6, (in Russian).

Samsonova, EA \& Efimova, EYu 2007, 'The youth of Tula: value orientations and realities of everyday life', Sotsiologicheskiye issledovaniya, no. 11, (in Russian).

Semenov, VE 2007, 'Value orientations and problems of education of modern youth', Sotsiologicheskiye issledovaniya, no. 4, (in Russian).

Sokolov, AV \& Shcherbakova, 10 2003, 'Value orientations of the post-Soviet humanitarian students', Sotsiologicheskiye issledovaniya, no. 1, (in Russian).

Tsvetkova, IV 2005, 'Health as a vital value of adolescents', Sotsiologicheskiye issledovaniya, no. 11, (in Russian). Russian).

Yavon, SV 2012, 'Value orientations of the youth of the Middle Volga region', Sotsiologicheskiye issledovaniya, no. 5, (in 